Gut, 1982, 23, 814-818

\title{
What does the antimitochondrial antibody mean?
}

\author{
D R TRIGER, ${ }^{*}$ C A C CHARLTON, and A MILFORD WARD \\ From the Departments of Medicine and Immunology, Royal Hallamshire Hospital, Sheffield
}

SUMMARY In a prospective survey positive antimitochondrial antibodies have been detected in $69 / 4200(1.64 \%)$ of all sera submitted to a routine immunology laboratory. Of the 69 , only nine patients had uniquivocal primary biliary cirrhosis, six others had chronic active hepatitis, 10 had abnormal liver function tests without evidence of primary biliary cirrhosis, while the remaining 44 had no clinical or biochemical evidence of liver disease. Outside the context of liver disease antimitochondrial antibodies were observed with similar frequency in patients with autoimmune disorders as in other conditions. It was not possible to distinguish primary biliary cirrhosis from patients without liver disease by antibody titre or by immunoglobulin subclass. The positive antimitochondrial antibody patients without liver disease were uniformly distributed throughout the city of Sheffield, in contrast with the marked clustering of cases of primary biliary cirrhosis. We conclude that, in the absence of clinical liver disease, the antimitochondrial antibody test alone (as detected by routine immunofluorescent techniques) does not appear to be a specific screening test for primary biliary cirrhosis. While we cannot exclude the possibility that the autoantibody indicates a predisposition to develop primary biliary cirrhosis, further prospective studies are needed to determine which patients will progress in this manner. The possibility that environmental factors may be implicated cannot be discounted.

The discovery of the antimitochondrial antibody as a marker for primary biliary cirrhosis has done much to clarify diagnostic problems of jaundice and liver disease. While a few studies have been performed to ascertain the prevalence of the antibody in the normal population, ${ }^{1-3}$ little is known about the diagnostic value of the antibody in the general population of patients attending hospitals for other than hepatobiliary disorders. Although Walker $e t a l^{4}$ investigated such a population during the 1960 s, the clinical material was heavily biased towards the patients with known or suspected immunological disorders. 'Autoimmune profiles' are now widely established as a routine investigation in many hospitals and, as a consequence of this, a number of antimitochondrial antibodies may be detected incidentally in the course of looking for other autoantibodies. The purpose of this study was to review all patients with positive antimitochondrial antibodies detected by a routine immunology laboratory in a large hospital with a view to answering the following questions: (1) what

\footnotetext{
* Address for correspondence: D R Triger, Department of Medicine, Royal Hallamshire Hospital, Sheffield S10 2JF, England.

Received for publication 8 February 1982
}

proportion of such patients had primary biliary cirrhosis? and (2) could further examination of the serum distinguish those with liver disease from the remainder?

This study was also prompted by the previously reported observation of clustering of cases of primary biliary cirrhosis within the city of Sheffield. ${ }^{5}$ This survey was intended to look for cases of the disease which might have escaped previous detection as well as to examine the geographical distribution of patients with positive antimitochondrial antibody within the city.

\section{Methods}

\section{MATERIALS}

All sera submitted to the immunology laboratory at the Royal Hallamshire Hospital, Sheffield, for any antibody investigation are routinely processed by a technique which permits detection of a wide range of autoantibodies. This survey covered all antimitochondrial antibody positive sera detected during the period 1 January 1978 to 31 March 1979. In order to make record retrieval easier the study was confined to investigations emanating from hospitals within the city of Sheffield. 
The antimitochondrial antibodies were determined by indirect immunofluorescence using cryostat sections cut from a composite block of rat kidney, liver, and stomach tissue. Sera were initially screened at a dilution of 1:20 using Polyvalent FITC conjugated swine antihuman immunoglobulin (Nordic Immunochemicals, Tilburg).

The medical records of all the patients with a positive antimitochondrial antibody were reviewed in an attempt to establish the clinical diagnosis. Patients could be divided into three broad categories: (1) those with evidence suggesting primary biliary cirrhosis based on compatible clinical, biochemical, and histological features; ${ }^{6}(2)$ those with evidence of liver disease but in whom a diagnosis of primary biliary cirrhosis could not be sustained using the above criteria; (3) patients in whom the primary clinical diagnosis was nonhepatic.

The broad diagnostic categories under which autoimmune profiles were requested were defined by scrutiny of random samples of request forms during the period in question.

Sera from 25 patients with a positive antimitochondrial antibody in whom no evidence of any primary hepatic disorder could be found were compared with those from 36 patients with established primary biliary cirrhosis for evidence of any serological differences. The antimitochondrial antibody titre was determined by mixing the sera with normal saline to dilutions of 1:40,1:80,1:200, and 1:1000. The immunoglobulin subclass was determined using rabbit antihuman $\mathrm{IgG}, \operatorname{IgA}$, and IgM fluorescein conjugated antisera (Behring, Marburg, West Germany).

The patient's address at the time of the antibody determination was obtained from the hospital records. Details concerning the source of the domestic water supply were obtained from the Yorkshire Water Authority (Southern Division).

\section{Results}

A positive antimitochondrial antibody of a titre of at least 1:20 was detected in 69 out of 4200 sera tested $(1.64 \%)$. An uniquivocal diagnosis of primary biliary cirrhosis could be established in nine patients, while another six had clinical, biochemical, and histological features more suggestive of chronic active hepatitis than primary biliary cirrhosis. Antinuclear antibody was additionally found in high titre in four of these six patients.

The large majority of the patients $(54 / 69)$ had no clinical signs or symptoms suggesting hepatocellular disease. In 44 patients routine liver function tests (bilirubin, alkaline phosphatase, albumin, and globulin, as well as serum transaminases in half of the patients) were entirely normal. Abnormalities were detected in the remaining 10 cases, four of whom underwent percutaneous liver biopsy. No significant abnormality was found in one patient, mild fatty change in another, and portal inflammatory changes in the other two. The latter patients were both known to have had a raised alkaline phosphatase and a positive antimitochondrial antibody for more than five years before biopsy, but neither had any clinical evidence of liver disease and in neither case could the liver biopsy be interpreted as being consistent with primary biliary cirrhosis. There was a marked female preponderance among the patients without liver disease $(36: 8)$, as is usually seen in primary biliary cirrhosis, but the patients without overt evidence of liver damage tended to be younger than patients with primary biliary cirrhosis (age range 20-75 years, mean 51.1 years vs 34-79 years, mean 58.8 years). ${ }^{5}$

Table 1 shows the primary diagnoses of these 69 patients expressed in absolute number as well as a percentage in each diagnostic category. Patients with collagen disorders comprise the largest single group but they also formed the largest diagnostic category for which autoantibody profiles were requested. Although the numbers were relatively small, a higher percentage of antimitochondrial antibodies were encountered in the neurological and dermatological patients. The seven positive antibodies in the neurological patients occurred in association with multiple sclerosis (four), mononeuritis multiplex (one), cervical spondylosis (one), and an upper motor neurone lesion of unknown aetiology (one). The patients with multiple sclerosis had high titre antimitochondrial antibody, negative antinuclear antibody, and did not have biological false positive reactions, in contrast with the 'lupoid sclerosis' syndrome described by Fulford and colleagues. $^{7}$

The diagnosis in the dermatology patients were lichen planus (two), psoriasis (one), and alopecia areata (one), the latter patient also having aphthous

Table 1 Positive AMA by diagnosis

\begin{tabular}{|c|c|c|c|}
\hline \multirow[b]{2}{*}{ Diagnosis } & \multirow{2}{*}{$\begin{array}{l}\text { Sera } \\
\text { (no.) }\end{array}$} & \multicolumn{2}{|c|}{$A M A+v e$} \\
\hline & & (no.) & $(\%)$ \\
\hline Liver disease & 480 & 15 & $3 \cdot 13$ \\
\hline Collagen disorders & 2205 & 21 & 0.95 \\
\hline Endocrine & 510 & 6 & $1 \cdot 18$ \\
\hline Neurology & 135 & 7 & $5 \cdot 18$ \\
\hline Dermatology & 90 & 4 & $4 \cdot 44$ \\
\hline Others & 780 & 16 & $2 \cdot 05$ \\
\hline Total & 4200 & 69 & $1 \cdot 64$ \\
\hline
\end{tabular}


ulceration, a positive antireticulin antibody but a normal jejunal biopsy and no evidence of malabsorption. The relatively high prevalence in all the groups, together with the 'miscellaneous' group, suggests that the association of antimitochondrial antibody with 'autoimmune disorders' may be less specific than has been hitherto assumed.

Antimitochondrial antibody positive sera from the patients with no evidence of liver disease were studied in greater detail for antibody titre and immunoglobulin class. A second sample of serum was requested from each patient in order to confirm the initial finding as well as to carry out these studies. As a number of patients had either died, moved away from the area, or were unwilling to provide such a sample, only 25 of the 54 samples could be retested. Review of the clinical records did not suggest that this was a biased sample.

The Figure shows the antimitochondrial antibody titre for this group of patients compared with that found in 36 patients with primary biliary cirrhosis. While the antibody titre in patients with this disorder tended to be higher than in those without overt liver disease, the overlap was so great as to be of little clinical value. In our laboratory the only discriminating feature was that, whereas in primary biliary cirrhosis there were no titres of less than $1: 80,7 / 25$ of the non primary biliary cirrhosis sera had titres in this range.

With regard to the immunoglobulin subclass, 23/36 patients with primary biliary cirrhosis had IgG antibody alone, nine had IgG and subsidiary IgM, while four had IgG and subsidiary IgA. In the

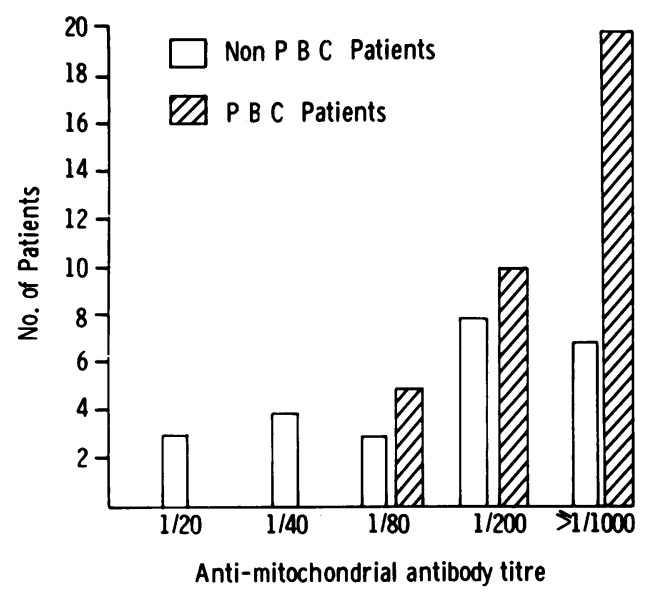

Figure Antimitochondrial antibody titres of 36 patients with primary biliary cirrhosis, compared with 25 patients without evidence of liver disease. non-liver disease group 21/25 had IgG antibody alone, one had IgG and subsidiary IgM, two IgG and subsidiary IgA (in both cases the antimitochondrial antibody was present only at a titre of $1: 40$ ), while a further patient had all three immunoglobulin classes.

Table 2 shows the geographical distribution of the non-liver disease antimitochondrial antibody positive cases throughout the city of Sheffield in relation to the domestic water supply and compares this with the population distribution in the city as well as with that observed for 43 cases of primary biliary cirrhosis which have been seen to date as part of a prospective survey of the disease within the city of Sheffield. ${ }^{5}$ In primary biliary cirrhosis the association with the water supply of Rivelin reservoir remains striking, as previously reported, whereas the distribution of the antimitochondrial antibody in the absence of liver disease closely parallels the population distribution throughout the city.

\section{Discussion}

We have observed a prevalence of antimitochondrial antibody in a titre of at least 1:20 in 1.69\% of serum samples received in a routine immunology laboratory. Even if patients with liver disease are excluded, the prevalence of 54/3720 (1.45\%) suggests that this is by no means a rare finding in the sera of patients attending hospital, and this figure compares closely with that of $1.5 \%$ reported among hospital inpatients in a West German study. ${ }^{8}$ While these represent selected populations, recent studies from Australia $^{2}$ and Sheffield ${ }^{3}$ suggest a prevalence in the normal adult population of $0.6 \%$ and $0.3 \%$. Our experience supports the previous observation that, in the context of clinical hepatobiliary disease

Table 2 Geographic distribution

\begin{tabular}{|c|c|c|c|}
\hline Reservoir & $\begin{array}{l}\% \text { City } \\
\text { population } \\
\text { supplied }\end{array}$ & $\begin{array}{l}\% A M A+v e \\
\text { non-liver } \\
\text { disease } \\
(n=44)\end{array}$ & $\begin{array}{l}\% P B C \\
(n=43)\end{array}$ \\
\hline Rivelin & 40 & 34 & 88 \\
\hline Langsett & 20 & 16 & - \\
\hline Bradfield & 15 & 18 & 5 \\
\hline Morehall & 10 & 14 & - \\
\hline Yorkshire Derwent & 7 & 2 & - \\
\hline Redmires & 7 & 19 & 7 \\
\hline Total & 100 & $103^{*}$ & 100 \\
\hline
\end{tabular}

* The figure exceeds 100 as two patients received their domestic supply in equal amounts from two different reservoirs. Otherwise the reservoir supplying the majority of the domestic water is quoted. 
the antimitochondrial antibody is a useful diagnostic test, although problems in classifying a small group of patients with chronic active hepatitis sometimes arise. $^{6}$

The majority of positive antimitochondrial antibodies were detected in patients who had no clinical or biochemical evidence of liver disease, let alone of primary biliary cirrhosis. While it has been previously recognised that the antibody may be associated with autoimmune disorders, ${ }^{4}$ this study suggests that it is found with comparable frequency in patients with a wide range of disorders which are not commonly associated with autoimmunity. The autoantibody in these patients does not appear to be obviously different from that seen in patients with unequivocal primary biliary cirrhosis. Twenty-eight per cent of our non-primary biliary cirrhosis patients had titres equal to or greater than 1:1000 and the overlap in the range of titres between the two groups is such that titration of the antibody cannot be used as a diagnostic test. Our limited experience would suggest that a screening dilution of 1:80 might eliminate many of the non-primary biliary cirrhosis antimitochondrial antibodies, but the recent report ${ }^{9}$ that some patients with primary biliary cirrhosis may have antibody titres of $1: 10$ or less makes it unlikely that there is any clear cut-off between primary biliary cirrhosis and non-primary biliary cirrhosis antimitochondrial antibody.

We have been careful to exclude other autoantibodies such as cardiolipin antibody, ${ }^{10}$ ribosomal RNA antibody, ${ }^{11}$ microsomal antibody, ${ }^{12}$ and heterophile brush border antibody ${ }^{13}$ which might be confused with the antimitochondrial antibody, but we cannot exclude some other subtle features which distinguish between different forms of antimitochondrial antibody as determined by immunofluorescence. Other techniques might enable us to distinguish between cases with primary biliary cirrhosis and those without, but the method used here is widely used in immunology laboratories ${ }^{14}$ and is that adopted by the pilot United Kingdom external quality assessment for autoantibodies.

Recently James and colleagues ${ }^{15}$ have reported a series of asymptomatic patients with positive antimitochondrial antibodies, liver histology consistent with primary biliary cirrhosis, and a variable propensity to develop progressive liver disease. Many of these patients had normal liver function tests, and we cannot exclude the possibility that many or most of our non-primary biliary cirrhosis group may ultimately develop clinical primary biliary cirrhosis. Liver biopsy was not considered to be ethically justifiable in any of the Sheffield patients who had no clinical or biochemical abnormalities, but in four asymptomatic patients with disturbed liver biochemistry the histological appearance was not consistent with primary biliary cirrhosis, despite several years' follow-up and repeat liver biopsy in two cases.

Our findings would suggest that the patients reported from Newcastle account for a minority of patients in whom a positive antimitochondrial antibody is detected incidentally in the course of investigation of non-hepatic disorders and similar results have recently been reported from Dundee, ${ }^{16}$ Southampton, ${ }^{17}$ and Bournemouth. ${ }^{18}$

Why some patients with antimitochondrial antibodies remain free of liver disease while others develop progressive hepatic damage is unknown, but the possibility that environmental factors might play a part cannot be discounted. The observation that the cases of established primary biliary cirrhosis in the city of Sheffield are clustered in certain geographic areas, whereas there is an even distribution of the non-primary biliary cirrhosis antimitochondrial antibody throughout the area is consistent with such a hypothesis, although the nature of the precipitating agent is unknown. Too few healthy subjects with positive antimitochondrial antibodies have been identified in a population survey in the city ${ }^{3}$ to enable any conclusions to be drawn about their geographical distribution.

Recent reports that D-penicillamine may favourably influence the progress of primary biliary cirrhosis ${ }^{19-21}$ make it important to define at an early stage patients with potentially progressive liver disease, as the drug is unlikely to alter prognosis once advanced cirrhosis is established. On the other hand, the toxicity of the drug makes it unacceptable as a long-term form of treatment in patients with little or no evidence of liver damage. The sole finding of a positive antimitochondrial antibody, even in high titre, does not appear to be an adequate screening test for such patients, although it may prove useful in identifying a group of individuals who require further investigation and follow-up.

\section{References}

1 Doniach D. Autoimmunity in liver disease. In: Schwartz RW, ed. Progress in clinical imunology. New York and London: Grune and Stratton, 1972; 1: 45-70.

2 Hawkins BR, O'Connor KJ, Dawkins RL, Dawkins B, Rodger B. Autoantibodies in an Australian population. I. Prevalence and persistence. J Lab Clin Med 1979; 2: 211-5.

3 Lennon CR. University of Sheffield: $B$ Med Sci. Thesis, 1981.

4 Walker JG, Doniach D, Doniach I. Mitochondrial 
antibodies and subclinical liver disease. $Q J$ Med 1970; 39: 31-48.

5 Triger DR. Primary biliary cirrhosis: an epidemiological study. $\mathrm{Br}$ Med J 1980; 281 : 772-5.

6 Klatskin G, Kantor FS. Mitochondrial antibody in primary biliary cirrhosis and other diseases. Ann Intern Med 1972; 77: 533-41.

7 Fulford KWM, Catterall RD, Delhanty JJ, Doniach D, Kremer M. A collagen disorder of the nervous system presenting as multiple sclerosis. Brain 1972; 95: 373-86.

8 Berg PA, Travenecker U, Marker A. Mitochondrial antibodies in non-hepatic disease. Germ Med Mth 1973; 3: 58.

9 Munoz LE, Thomas HC, Scheuer PJ, Sherlock S. Is mitochondrial antibody diagnostic of primary biliary cirrhosis? Gut 1981; 22: 136-40.

10 Doniach D, Delhanty J, Lindqvist HJ, Catterall RD. Mitochondrial and other tissue autoantibodies in patients with biological false positive reactions for syphilis. Clin Exp Immunol 1970; 6: 871-84.

11 Homberg JC, Rizzetto M, Doniach D. Ribosomal antibodies detected by immunofluorescence in systemic lupus erythematosus and other collagenoses. Clin Exp Immunol 1974; 17: 617-28.

12 Rizzetto M, Swann G, Doniach D. Microsomal antibodies in active chronic hepatitis and other disorders. Clin Exp Immunol 1973; 15: 331-44.

13 Ireton HJC, Muller HK, McGiven AR. Human antibody against rat gastric parietal cells and kidney brush boarder. Clin Exp Immunol 1971; 8: 783-9.

14 Johnson GD, Dorling J. Immunofluorescence and immunoperoxidase techniques. In: Thompson RA, ed. Techniques in clinical immunology. Oxford: Blackwell, 1981: 100-37.

15 James O, Macklon AF, Watson AJ. Primary biliary cirrhosis - a revised clinical spectrum. Lancet 1981; 1: 1278-81.

16 Hislop WS, Main G, Robertson AJS. Primary biliary cirrhosis: experience in a non-referral centre. Lancet 1981; 2: 144.

17 Hodges JR, Hall AJ, Wright R. Primary biliary cirrhosis and antimitochondrial antibodies. Lancet 1981; 2: 362.

18 Hamblin TJ. Significance of antimitochondrial antibodies. Lancet 1981; 2: 1411-2.

19 Epstein O, Jain S, Lee RG, Cook DG, Boss AM, Scheuer PJ, Sherlock S. D-Penicillamine treatment improves survival in primary biliary cirrhosis. Lancet 1981; 1: 1275-7.

20 Fleming CR, Lindor KD, Dickson ER, Ludwig J, Baldus WP. D-Pencillamine in primary biliary cirrhosis. Apparent beneficial effects in spite of a lack of correlation with changes in hepatic copper concentration. Gastroenterology 1978; 75: A964.

21 Triger DR, Manifold IH, Cloke P, Underwood JCE. D-Pencillamine in primary biliary cirrhosis: two year results of a single centre, double-blind controlled trial. Gut 1980; 21: A919-20. 